\title{
Cellular and Behavioral Interactions of Gabapentin with Alcohol Dependence
}

\author{
Marisa Roberto, ${ }^{1,3}$ Nicholas W. Gilpin, ${ }^{1}$ Laura E. 0’Dell, ${ }^{4}$ Maureen T. Cruz, ${ }^{1}$ Andrew C. Morse, ${ }^{5}$ George R. Siggins, ${ }^{2}$ and \\ George F. Koob ${ }^{1,3}$ \\ ${ }^{1}$ Committee on the Neurobiology of Addictive Disorders, ${ }^{2}$ Department of Molecular and Integrative Neurosciences, and ${ }^{3}$ Pearson Center for Alcoholism and \\ Addiction Research, The Scripps Research Institute, La Jolla, California 92037, ${ }^{4}$ Department of Psychology, University of Texas at El Paso, El Paso, Texas \\ 79902, and ${ }^{5}$ BrainCells, San Diego, California 92121
}

Gabapentin is a structural analog of GABA that has anticonvulsant properties. Despite the therapeutic efficacy of gabapentin, its molecular and cellular mechanisms of action are unclear. The GABAergic system in the central nucleus of the amygdala (CeA) plays an important role in regulating voluntary ethanol intake. Here, we investigated the effect of gabapentin on GABAergic transmission in CeA slices, on ethanol intake, and on an anxiety measure using animal models of ethanol dependence. Gabapentin increased the amplitudes of evoked GABA receptor-mediated IPSCs (GABA-IPSCs) in CeA neurons from nondependent rats, but decreased their amplitudes in CeA of ethanol-dependent rats. Gabapentin effects were blocked in the presence of a specific $\mathrm{GABA}_{B}$ receptor antagonist. The sensitivity of the GABA-IPSCs to a $\mathrm{GABA}_{\mathrm{B}}$ receptor antagonist and an agonist was decreased after chronic ethanol, suggesting that ethanol-induced neuroadaptations of $\mathrm{GABA}_{\mathrm{B}}$ receptors associated with ethanol dependence may account for the differential effects of gabapentin after chronic ethanol. Systemic gabapentin reduced ethanol intake in dependent, but not in nondependent, rats and reversed the anxiogeniclike effects of ethanol abstinence using an acute dependence model. Gabapentin infused directly into the CeA also blocked dependenceinduced elevation in operant ethanol responding. Collectively, these findings show that gabapentin reverses behavioral measures of ethanol dependence and, in turn, dependence reverses the effects of gabapentin on CeA neurons, and suggest that gabapentin represents a potential medication for treatment of alcoholism.

Key words: amygdala; ethanol dependence; IPSC; paired-pulse facilitation; anxiety; ethanol-self administration

\section{Introduction}

Gabapentin, an amino acid designed as a structural analog of GABA (Sills, 2006), is a novel anticonvulsant drug that came into clinical use as adjunctive therapy in the treatment of human seizures. However, its mechanism of pharmacological action remains unknown. Gabapentin increases (1) the concentration and probably the synthesis of GABA in the brain (Taylor et al., 1998), (2) GABA release from rat striatal brain slices in vitro (Gotz et al., 1993), and (3) the nonvesicular release of GABA in rat optic nerves (Kocsis and Honmou, 1994) and rat hippocampal slices (Honmou et al., 1995). Gabapentin also decreases monoaminergic synaptic transmission in rat hippocampus and neocortex by selectively inhibiting $\mathrm{Ca}^{2+}$ influx through voltage-operated $\mathrm{Ca}^{2+}$ channels (VOCCs) (Fink et al., 2000; Dooley et al., 2002; van Hooft et al., 2002). In addition, gabapentin is an agonist for the endogenously expressed $\mathrm{GABA}_{\mathrm{B}} \mathrm{gbla}-\mathrm{gb} 2$ heteromers cou-

Received Jan. 17, 2007; revised April 21, 2008; accepted April 21, 2008.

This work was supported by National Institutes of Health Grants AA013517 (National Institute on Alcohol Abuse and Alcoholism-Funded Integrative Neuroscience Initiative on Alcoholism), AA015566, and AA06420, the Harold L. Dorris Neurological Research Institute, and The Scripps Research Institute (M.R.). We thank Drs. Floyd E. Bloom Melanie Tallent, and Michal Bajo for critical comments on this manuscript, and Dr. Heather Richardson and Sam Madamba for technical assistance.

Correspondence should be addressed to Dr. Marisa Roberto, The Scripps Research Institute, SP-30-1160, 10550 North Torrey Pines Road, La Jolla, CA 92037. E-mail: mroberto@scripps.edu.

DOI:10.1523/JNEUROSCI.0575-08.2008

Copyright $\odot 2008$ Society for Neuroscience $\quad$ 0270-6474/08/285762-10\$15.00/0 pled to inhibition of VOCCs in intermediate pituitary melanotrope cell lines and in hippocampal neurons (Bertrand et al., 2001; Ng et al., 2001; van Hooft et al., 2002).

Gabapentin has been used effectively in the treatment of alcohol withdrawal in alcoholics (Bonnet et al., 1999, 2007; Bozikas et al., 2002; Gentry et al., 2002; Voris et al., 2003; Book and Myrick, 2005; Mariani et al., 2006; Myrick et al., 2007) and has a selective action in decreasing the convulsive and anxiety-related signs of ethanol withdrawal in mice (Watson et al., 1997). Gabapentin decreases ethanol-induced anxiety-like behavior in the elevated plus maze, but has no effect on motor coordination or spontaneous locomotor activity in control mice (Watson et al., 1997).

In the present study, we tested the effects of gabapentin on GABAergic synapses in the central amygdala (CeA), a brain region considered pivotal in the behavioral effects of acute and chronic ethanol consumption. We also tested the hypothesis that gabapentin has motivational effects on ethanol selfadministration in an animal model of ethanol dependence. Most CeA neurons are GABAergic (Sun and Cassell, 1993; Cassell et al., 1999), either inhibitory neurons with recurrent or feedforward connections or inhibitory projection neurons to brainstem or other downstream regions (e.g., bed nucleus of the stria terminalis). The CeA can be characterized as a "gate" that regulates the flow of information through intra-amygdaloidal circuits, changing the excitability of local and downstream circuitries. Acute 
ethanol augments GABAergic transmission in rat CeA neurons through a $\mathrm{GABA}_{\mathrm{B}}$ receptor-independent mechanism (Roberto et al., 2003), the latter in contrast to other brain regions [e.g., hippocampus (Wan et al., 1996) and NAcc (Nie et al., 2000)]. In addition, in CeA slices taken from ethanol-dependent rats, acute ethanol increases $\mathrm{GABA}_{\mathrm{A}}$ receptor-mediated IPSCs $\left(\mathrm{GABA}_{\mathrm{A}}{ }^{-}\right.$ IPSCs) to the same extent as in slices from naive rats, suggesting a lack of tolerance (Roberto et al., 2004a). Here, we show that gabapentin, like ethanol, increases evoked IPSC amplitudes in association with a decrease in paired-pulse facilitation (PPF) of $\mathrm{GABA}_{\mathrm{A}}$-IPSCs in CeA neurons from nondependent rats. However, in ethanol-dependent rats, gabapentin had effects opposite to those of ethanol, decreasing IPSCs and increasing PPF in the CeA. Superfusion of a $\mathrm{GABA}_{\mathrm{B}}$ receptor antagonist blocked the effect of gabapentin on the amplitude or PPF of the $\mathrm{GABA}_{\mathrm{A}^{-}}$ IPSCs. Interestingly, the sensitivity of GABA-IPSCs to the $\mathrm{GABA}_{\mathrm{B}}$ receptor antagonist and agonist was decreased after chronic ethanol. Systemic administration of gabapentin dosedependently reduced ethanol intake in dependent, but not in nondependent rats, and local injection of gabapentin into CeA reversed the increased ethanol intake in dependent rats. Gabapentin also suppressed anxiety-like behavior in a model of acute ethanol withdrawal-induced anxiety. These results suggest that gabapentin may regulate ethanol intake and anxiety-related behavior associated with ethanol dependence via synaptic actions in the amygdala.

\section{Materials and Methods}

\section{Electrophysiological studies}

Slice preparation. We prepared CeA slices as described previously (Roberto et al., 2003, 2004a), from male Wistar rats (200-300 g; 4-7 weeks old) that were anesthetized with halothane $(3 \%)$ and decapitated. The brains were rapidly removed and placed into ice-cold artificial CSF (aCSF) gassed with $95 \% \mathrm{O}_{2}$ and $5 \% \mathrm{CO}_{2}$. We cut transverse slices $400 \mu \mathrm{m}$ thick on a Vibratome Series 3000 (Technical Products International), incubated them in an interface configuration for $\sim 30 \mathrm{~min}$, and then completely submerged and continuously superfused (flow rate of 2-4 $\mathrm{ml} / \mathrm{min})$ them with warm $\left(31^{\circ} \mathrm{C}\right)$ gassed ACSF of the following composition (in mM): $130 \mathrm{NaCl}, 3.5 \mathrm{KCl}, 1.25 \mathrm{NaH}_{2} \mathrm{PO}_{4}, 1.5 \mathrm{MgSO}_{4} \cdot 7 \mathrm{H}_{2} \mathrm{O}, 2.0$ $\mathrm{CaCl}_{2}, 24 \mathrm{NaHCO}_{3}$, and 10 glucose. The inner chamber had a total volume of $0.8 \mathrm{ml}$. Drugs were added to the ACSF from stock solutions to obtain known concentrations in the superfusate. At the $2-4 \mathrm{ml} / \mathrm{min}$ superfusion rates used, drug concentrations reach $90 \%$ of the reservoir concentration within 2 min.

Chronic ethanol treatment. We used the standard ethanol inhalation method of The Scripps Research Institute Alcohol Research Center to induce ethanol dependence in rats (Rogers et al., 1979; Roberto et al., 2004a,b). Briefly, male Wistar rats were housed 2-4 per cage on a 6:00 A.M. to 6:00 P.M. light cycle, with ad libitum access to food and water. Rats were exposed to either ethanol vapor or ambient air (sham naive controls). Ethanol-treated rats were continuously exposed to ethanol vapors for 2-4 weeks as described previously (Roberto et al., 2004a,b). We handled sham controls similarly but without exposure to ethanol vapor. On experiment days, the chronic ethanol-treated rats were maintained in the ethanol vapor chamber until preparation of the CeA slices. We made recordings in ethanol-free ACSF from slices of ethanoldependent rats $2-8 \mathrm{~h}$ after cutting the slices, as described previously (Roberto et al., 2004a).

Alcohol liquid diet exposure. During ethanol liquid diet exposure, the sole source of nutrition available to rats in the home cage was the ethanol or control liquid diet, although water was still available to all rats ad libitum. One liter of ethanol liquid diet contained $3 \mathrm{~g}$ of vitamins (MP Biomedicals), $5 \mathrm{~g}$ of salt (MP Biomedicals), $92 \mathrm{ml}$ of $95 \% \mathrm{v} / \mathrm{v}$ ethanol, 711 $\mathrm{ml}$ of Boost (high-protein chocolate-flavored nutritional energy drink), and $197 \mathrm{ml}$ of water; $1 \mathrm{~L}$ of control liquid diet was similar except that it contained $126 \mathrm{~g}$ of sucrose (isocalorically matched to ethanol liquid diet;
Sigma-Aldrich) instead of $95 \% \mathrm{v} / \mathrm{v}$ ethanol. Control diet availability for nondependent rats was yoked to intakes of ethanol liquid diet by dependent rats on the previous day, and standardized for body weights. At these concentrations, rats derived $41 \%$ of their caloric intake from ethanol/sucrose.

BAL and body weight. We determined blood alcohol levels (BALs) of the ethanol-dependent animals from tail-blood samples taken three times per week. Control animals were also routinely sampled to control for possible effects of handling. The mean BAL of all ethanol-dependent animals was $176.2 \pm 11 \mathrm{mg} / \mathrm{dl}(n=33)$. The mean body weight of ethanol-dependent animals was $245 \pm 12 \mathrm{~g}(n=24)$, compared with a mean body weight of $249 \pm 20 \mathrm{~g}(n=18)$ for sham control animals. We conducted all procedures in accordance with the National Institutes of Health Guide for the Care and Use of Laboratory Animals.

Electrophysiology. We recorded from CeA neurons with sharp micropipettes $(3 \mathrm{M} \mathrm{KCl})$ using discontinuous voltage- or current-clamp mode. In voltage-clamp mode, we used a switching frequency of $3-5 \mathrm{kHz}$ and, on a separate oscilloscope, continuously monitored electrode settling time and capacitance neutralization at the headstage. We held most neurons near their resting membrane potential (RMP). Data were acquired with an Axoclamp-2A preamplifier (Molecular Devices) and stored for later analysis using pClamp software (Molecular Devices). We evoked pharmacologically isolated GABA-IPSCs by stimulating locally within the CeA through a bipolar stimulating electrode while superfusing the slices with the glutamate receptor blockers 6-cyano-7-nitroquinoxaline-2,3-dione (CNQX; $10 \mathrm{~mm}$ ) and DL-2-amino-5-phosphonovalerate (APV; $30 \mu \mathrm{M})$. In some cells, we also applied $1 \mu \mathrm{M}$ (2S)-3[[(1S)-1-(3,4-dichlorophenyl)-ethyl] amino-2-hydroxypropyl](phenylmethyl)phosphinic acid hydrochloride [CGP 55845A $(\mathrm{CGP})$; $\mathrm{a} \mathrm{GABA}_{\mathrm{B}}$ receptor antagonist] to further isolate $\mathrm{GABA}_{\mathrm{A}}$ receptormediated IPSCs. At the end of the recording, to confirm the GABAergic nature of the IPSC, we often superfused (1 $\mu \mathrm{M})$ CGP 55845A and $30 \mu \mathrm{M}$ bicuculline (or $50 \mu \mathrm{m}$ picrotoxin); these antagonists completely blocked the IPSCs (see Fig. $1 B$ ). Initially, we evoked IPSCs during superfusion of gabapentin $(10-75 \mu \mathrm{M} ; \sim 0.09-0.64 \mu \mathrm{g} / \mathrm{ml})$ and we used the maximal concentration ( $50 \mu \mathrm{M} ; \sim 0.43 \mu \mathrm{g} / \mathrm{ml}$ ) of gabapentin in all subsequent electrophysiological experiments. To determine the response parameters for each cell, we performed an input-output $(I-O)$ protocol (at least three times for each experimental condition: baseline, drug, and wash). A range of incrementally adjusted currents was applied (typically between 50 and $250 \mathrm{~mA} ; 0.125 \mathrm{~Hz}$ ), starting at the threshold current required to elicit an IPSC up to the voltage required to elicit the maximum amplitude. We maintained the stimulus strengths throughout the entire duration of the experiment. We normalized three stimulus intensities of equal steps (threshold, half-maximal, and maximal) as $1-3 \times$. Hyperpolarizing and depolarizing current steps $(200 \mathrm{pA}$ increments, $750 \mathrm{~ms}$ duration) were also applied to generate voltage-current $(V-I)$ curves. We quantified the evoked IPSC amplitudes and $V-I$ responses by using Clampfit software (Molecular Devices).

We examined PPF in each neuron using $50 \mathrm{~ms}$ interstimulus intervals (Roberto et al., 2004a). The stimulus strength was adjusted such that the amplitude of the first IPSC was 50\% of maximal, determined from the $I-O$ relationship. We calculated the paired-pulse ratio (average of three sequential paired-pulse IPSCs evoked at half-maximal intensity stimuli, $30 \mathrm{~ms}$ intervals between sets of paired pulse stimuli) as the second IPSC amplitude over that of the first IPSC amplitude. All measures were taken before gabapentin or ethanol superfusion (control), during their superfusion (5-10 $\mathrm{min})$, and after washout (20-30 $\mathrm{min})$. We normalized all values to percentage of control and expressed them as mean \pm SEM. Data were analyzed with a between-subjects ANOVA or within-subjects ANOVA with repeated measures and, when appropriate, with the Newman-Keuls post hoc test with $p<0.05$ considered statistically significant. In some cases, we used a Student's paired or unpaired $t$ test for individual means comparisons.

Drugs. CGP 55845A was a gift from Novartis Pharma. We purchased D-AP5, CNQX, picrotoxin, baclofen, and bicuculline from Sigma, gabapentin from ChemPacific, and ethanol from Remet.

\section{Behavioral studies}

Effects of systemic gabapentin on ethanol intake. Male Wistar rats (250$300 \mathrm{~g}$ at the start of training) were initially trained to self-administer $10 \%$ 
$(\mathrm{w} / \mathrm{v})$ ethanol in daily $30 \mathrm{~min}$ operant sessions via the use of a saccharin fading procedure (Funk et al., 2006). Once operant responding stabilized, we divided rats into two groups matched for ethanol responding and exposed them to either ethanol vapor (dependent group; $n=14$ ) or ambient air (nondependent group; $n=14$ ) for a period of at least 4 weeks. Tail blood samples were collected several times per week, and BALs were maintained in a range of $150-200 \mathrm{mg} \%$. Doses of gabapentin tested in the present study are comparable with those tested in human studies of alcohol-drinking behavior and craving [300-1200 mg daily (Myrick et al., 2007), which produces a plasma level of $\sim 40 \mu \mathrm{M} / \mathrm{ml}$ (Dierking et al., 2004)], and these doses are defined by high tolerability, few side effects, and low dropout rates in subjects (for review, see Pappagallo, 2003). We tested five doses $(0,5,10,30$, and $120 \mathrm{mg} / \mathrm{kg}$, i.p.) of gabapentin in a within-subjects Latin-square design; two tests occurred per week. On test days, rats were removed from vapor chambers, and blood was collected immediately from tails for BAL determination. Rats were injected with gabapentin 90 min later, returned to the home cage for a $30 \mathrm{~min}$ wait period, and then tested for operant ethanol selfadministration $2 \mathrm{~h}$ after termination of vapor inhalation. After testing, rats were immediately returned to vapor chambers. We analyzed data with two-way (vapor history $x$ gabapentin dose) mixed-design ANOVAs and, when appropriate, with the Student-Newman-Keuls post hoc test, with $p<0.05$ considered statistically significant.

Effects of intra-CeA gabapentin on ethanol intake. We initially trained Male Wistar rats to self-administer $10 \%(\mathrm{w} / \mathrm{v})$ ethanol in daily $30 \mathrm{~min}$ operant sessions in the manner described above. Once operant responding stabilized, rats were divided into groups matched for ethanol responding and exposed to either ethanol-containing liquid diet (dependent group; $n=9$ ) or a calorically matched control liquid diet (nondependent group; $n=8$ ) for a period of $\sim 14$ weeks. We collected tail bloods at various time points during the dark cycle; rats consumed quantities of ethanol liquid diet sufficient to achieve BALs between $192.10 \pm 18.26 \mathrm{mg} \%$ and $233.67 \pm 13.93 \mathrm{mg} \%$. During this 14 week period, we tested rats twice per week at $6 \mathrm{~h}$ withdrawal for operant ethanol responding. After establishment of stable operant responding across test days in dependent and nondependent rats, all rats underwent stereotaxic surgery and were implanted bilaterally with cannulas aimed at the CeA. Subsequently, rats underwent a series of "sham" infusions to habituate to the procedure and were then infused with four NPY doses in a Latin-square design plus twice with aCSF. Those NPY data are part of another study not presented here, but operant response data after vehicle infusion during the gabapentin Latin-square design did not significantly differ from operant response data after vehicle infusion before the NPY Latin square. After a washout period of $14 \mathrm{~d}$, we tested rats for the effects of gabapentin $(20 \mu \mathrm{g})$ or vehicle infused directly into the CeA on operant ethanol intake. These gabapentin/vehicle infusions were administered in a within-subjects Latin-square design. On operant test days, we removed liquid diet bottles and recorded intakes $2 \mathrm{~h}$ before the start of the dark cycle (8:00 A.M.). Six hours later ( $4 \mathrm{~h}$ into the dark cycle), rats were infused with gabapentin and, after a $30 \mathrm{~min}$ wait period, tested for operant alcohol responding. After all experimental procedures, cannula placements, and patency were histologically verified. We analyzed data with two-way (vapor history by gabapentin dose) mixed-design ANOVAs and, when appropriate, with Student-Newman-Keuls post hoc $t$ tests, with $p<0.05$ considered statistically significant.

Stereotaxic surgeries. We surgically implanted cannulas using aseptic procedures as described previously (Funk et al., 2006). We determined the stereotaxic coordinates (anteroposterior, -2.6 ; mediolateral, \pm 4.2 ; dorsoventral, -5.2 relative to bregma from skull surface) according to Paxinos and Watson (1986). We implanted rats bilaterally with two cannulas aimed at the CeA. The injection cannula (33 gauge) extended 1.0 $\mathrm{mm}$ beyond the tip of the guide cannula ( 26 gauge) when inserted (components from Plastics One). Before further manipulation, we monitored the rats during $7 \mathrm{~d}$ of recovery to determine that the animal had resumed normal activity such as mobility, feeding, and drinking.

Microinfusions. We used a Harvard 33 microinfusion pump for all drug infusions (rate of $0.25 \mu \mathrm{l} / \mathrm{min}$ for $2 \mathrm{~min}$ ), and left the injection cannula in the guide cannula for 1 additional minute to allow for adequate diffusion of the solution. We delivered infusions to the cannula via polyethylene tubing (PE 20) that was connected to a Hamilton $10 \mu \mathrm{l}$ syringe. After infusions, we immediately placed rats in operant boxes; sessions started $30 \mathrm{~min}$ after the end of infusions.

Gabapentin effects on anxiety-like behavior produced by bolus injection of acute ethanol. Acute bolus injections of ethanol produce elevations in anxiety-like behavior after BALs return to zero, and this elevated anxietylike behavior has been validated as a measure of acute withdrawal (Lal et al., 1991; Jung et al., 2000). We injected male Wistar rats with saline or $10 \%(\mathrm{w} / \mathrm{v})$ ethanol (3 g/kg, i.p.). Ten hours later, we placed the rats in the center of an elevated plus maze and allowed them to explore the closed and open arms of the apparatus for a 5 min period. Previous experiments (Morse et al., 2000) showed that BALs are undetectable $10 \mathrm{~h}$ after bolus injection of $3 \mathrm{~g} / \mathrm{kg}$ ethanol. Thirty minutes before anxiety testing, separate groups of rats were injected with one of several doses of gabapentin $(0,30,60$, or $120 \mathrm{mg} / \mathrm{kg}$, i.p; $n=8-10$ per dose $)$. We analyzed data (percentage of time spent in open arms of plus maze) with two-way (injection solution $\times$ gabapentin vs vehicle) between-subjects ANOVAs and, when appropriate, with the Student-Newman-Keuls post hoc test, with $p<0.05$ considered statistically significant.

\section{Results}

\section{Electrophysiological studies}

Gabapentin enhances GABAergic synaptic transmission in CeA neurons from nondependent rats

We recorded from a total of $140 \mathrm{CeA}$ neurons (mean RMP, $-76 \pm 1.9 \mathrm{mV})$. Gabapentin $(10-75 \mu \mathrm{M})$ did not significantly alter RMP, input resistance, or spike amplitudes in CeA neurons (data not shown). Superfusion (10 min) of 10-75 $\mu$ M gabapentin dose-dependently increased the amplitude of GABA-IPSCs (Fig. 1A) (mean increase over all three stimulus strengths). This gabapentin-IPSC interaction in CeA had an apparent $\mathrm{EC}_{50}$ value of 27 $\mu \mathrm{M}$ (Fig. 1A). The $50 \mu \mathrm{M}$ concentration of gabapentin produced a maximal increase in the mean amplitude of evoked GABAIPSCs (by 40\%) measured over all stimulus strengths (Fig. 1B) $(n=8)$. Therefore, the $50 \mu \mathrm{M}$ concentration was used in all subsequent electrophysiological experiments. This augmentation of GABA-IPSCs was blocked or occluded, at least in part (compare Fig. $4 B$ ), by $1 \mu \mathrm{M}$ CGP, a $\mathrm{GABA}_{\mathrm{B}}$ receptor antagonist (Fig. $1 B)(n=5)$. Subsequent superfusion of CGP 55845A, together with $30 \mu \mathrm{M}$ bicuculline (Fig. $1 B$ ) or $50 \mu \mathrm{M}$ picrotoxin (data not shown) $(n=3)$, completely blocked the IPSCs. To test whether this synaptic effect could derive from a presynaptic site of action, we examined PPF of the GABA-IPSCs. Generally, changes in PPF are inversely related to the probability of transmitter release (Andreasen and Hablitz, 1994; Roberto et al., 2003). Gabapentin significantly $(p<0.05)$ decreased PPF of GABA-IPSCs $(n=8)$ (Fig. $1 C)$, suggesting increased GABA release. However, in the presence of CGP 55845A, gabapentin did not decrease the PPF ratio $(n=5)$ (Fig. $1 C)$, suggesting that gabapentin enhances GABAergic transmission in CeA via a presynaptic $\mathrm{GABA}_{\mathrm{B}}$ receptor-related mechanism.

Because gabapentin, like ethanol (Roberto et al., 2003), increased IPSC amplitudes in CeA neurons, we superfused gabapentin alone and then coapplied ethanol with gabapentin onto CeA slices from naive rats to investigate the possibility of a common mechanism (Fig. $2 A$ ). In the presence of $50 \mu \mathrm{M}$ gabapentin, $44 \mathrm{~mm}$ ethanol, a maximally effective concentration (Roberto et al., 2003, 2004a) still increased GABA-IPSCs (Fig. 2A) and further decreased PPF (Fig. $2 B$ ).

\section{Gabapentin decreases GABA-IPSCs in CeA neurons from ethanol-dependent rats}

We previously reported an increased baseline GABAergic transmission and a persistent acute ethanol-induced increase of GABA release in CeA neurons of ethanol-dependent rats (Roberto et al., 
A

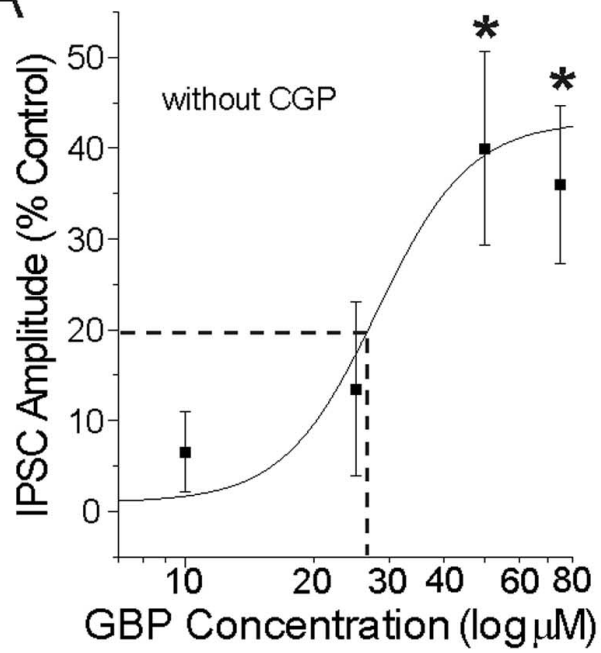

B

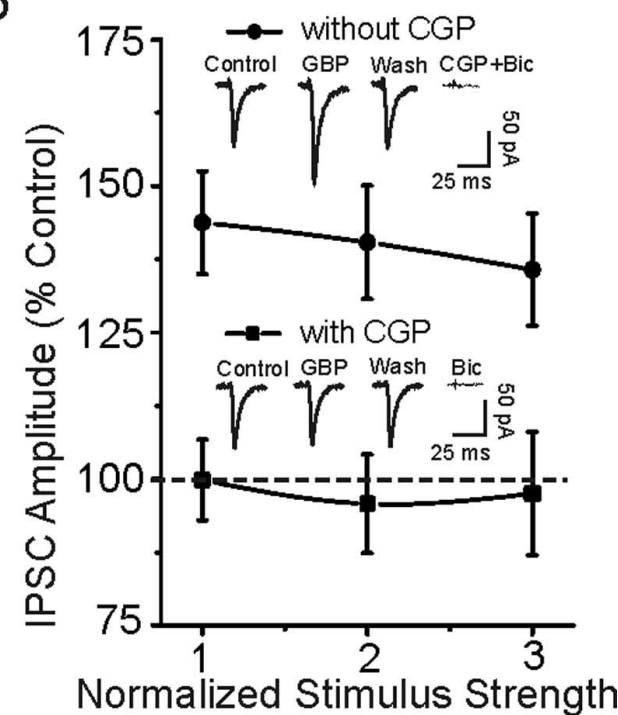

C

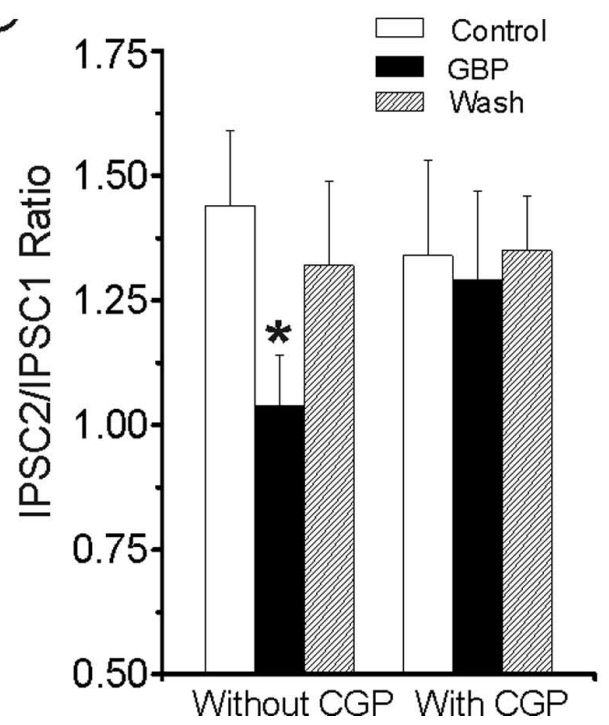

Figure 1. Gabapentin dose-dependently increases basal GABAergic transmission in the CeA from nondependent rats through a $G A B A_{B}$ receptor-related mechanism. $A$, Concentrationresponse relationship for gabapentin $(10,25,50$, and $75 \mu \mathrm{m})$ enhancement of mean IPSC amplitudes in CeA neurons, expressed as a percentage of control (number of cells for the 4 doses:
2003, 2004a), suggesting a lack of tolerance to the acute ethanol effects on GABA release. Therefore, we tested the effects of gabapentin on basal GABAergic transmission after chronic ethanol exposure. In direct contrast to the $\mathrm{CeA}$ of nondependent rats, gabapentin significantly $(p<0.05)$ decreased the mean GABAIPSC amplitude (to $65 \%$ of control; $n=7$ ) (Fig. $3 A$ ) in the CeA of dependent rats. Subsequent superfusion of CGP 55845A and bicuculline completely blocked these IPSCs. Furthermore, baseline PPF of GABA-IPSCs was significantly $(p<0.05)$ less in neurons from dependent rats compared with that of nondependent rats, suggesting that the probability of basal GABA release was augmented after chronic ethanol (Fig. 3B) (Roberto et al., 2004a). However, gabapentin significantly $(p<0.05)$ increased PPF of GABA-IPSCs $(n=6)$ (Fig. $3 B)$, suggesting that the drug decreased GABA release in CeA from dependent rats. This decrease of GABA-IPSCs was also blocked by CGP 55845A (to $96 \pm$ $5 \%$, mean across three stimulus intensities, $p>0.05 ; n=4$ ) (data not shown). Furthermore, acute ethanol $(44 \mathrm{~mm})$ significantly $(p<0.05)$ decreased the PPF of GABA-IPSCs (Fig. 3B) (Roberto et al., 2004a), indicating both increased GABA release and a lack of tolerance for this acute ethanol effect. To test the ethanolgabapentin interactions in CeA of dependent rats, the same protocol of Figure $2 B$ was repeated, where gabapentin was first superfused alone and then coapplied with ethanol. In the presence of gabapentin, acute ethanol (44 mM) significantly $(p<0.05 ; n=$ 7) overcame the depressive effect of gabapentin (Fig. 3C).

To determine whether $\mathrm{GABA}_{\mathrm{B}}$ receptors regulate evoked GABAergic transmission per se, we superfused $1 \mu \mathrm{M}$ CGP 55845A. CGP 55845A significantly ( $p<0.05 ; n=13$ ) increased the mean amplitude of evoked IPSCs (by $12 \pm 5 \%$, averaged over all stimulus intensities) in CeA from naive rats (Fig. 4A). This increase in the IPSC amplitude was associated with a significant $(p<0.05)$ decrease in PPF, suggesting a tonic activation of presynaptic $\mathrm{GABA}_{\mathrm{B}}$ receptors in naive rats (Fig. $4 C$ ). In contrast, in CeA from ethanol-dependent rats, CGP 55845A did not alter the mean evoked IPSCs (98 $\pm 4 \%$, averaged over all stimulus intensities; $n=10$ ) (Fig. 4A) and did not affect mean PPF (Fig. 4C). Figure $4 B$ shows the time course for CGP 55845A effects on IPSCs evoked at half-maximal stimulus intensity from both naive and ethanol-dependent rats. CGP 55845A significantly increased the amplitude of IPSCs only in CeA of naive rats.

We next examined whether chronic ethanol treatment (CET) affects the sensitivity of CeA synapses to baclofen, a $\mathrm{GABA}_{\mathrm{B}}$ agonist. Baclofen $(10 \mu \mathrm{M})$ markedly depressed evoked GABA-IPSC amplitudes in neurons of naive rats (to $38 \%$ of control; $n=11$; averaged over all stimulus intensities) (Fig. $4 D$ ), with recovery during washout $(20 \mathrm{~min})$. The baclofen-induced inhibition of GABA-IPSCs was significantly ( $p<0.001$ ) reduced (to $86 \%$ of control; $n=10$ ) in neurons of CET rats (Fig. $4 D$ ). In addition, in

\footnotetext{
$3,5,8$, and 4 respectively). The logistic curve, plotted by Origin Software (Microcal), using $y=$ $(A 1-A 2) /(1+(x / x 0) \times p+A 2)$, gives an apparent $\mathrm{EC}_{50}$ value (dashed line) of $27 \mu \mathrm{m}$ gabapentin for IPSC enhancement. Parameters of the logistic curve were set at: upper asymptote fixed at $140 \%$ and lower at $100 \%$. Rate was fixed at 4.0, with "center" unfixed. Error bars indicate SEM. ${ }^{*} p<0.05$. B, Gabapentin (50 $\mu$ M) superfusion for 10 min significantly ( $p<$ 0.05 ) increased the mean amplitudes of evoked GABA-IPSCs without (solid circles; $n=8$ ), but not with (solid squares; $n=5$ ) coapplication of $1 \mu \mathrm{m} \mathrm{CGP,} \mathrm{a} \mathrm{GABA}$ receptor antagonist. Note that CGP completely blocked the gabapentin-induced enhancement of IPSCS. Inset, Representative recordings of evoked IPSCS. Superfusion of GABA and GABA $A_{B}$ receptor blockers completely blocked these IPSCS. C, Gabapentin $(50 \mu \mathrm{m})$ significantly $\left({ }^{*} p<0.05\right)$ decreased the mean PPF of IPSCs only in the absence of CGP. The mean ( \pm SEM) of the paired-pulse ratio is expressed as IPSC2/IPSC1.
} 
CET neurons $(n=7)$, baclofen-induced depression was associated with a smaller increase of the PPF ratio of $\mathrm{GABA}_{\mathrm{A}}$-IPSCs compared with that in neurons of naive rats $(n=6)$ (Fig. $4 E, F)$.

\section{Behavioral studies}

Effects of systemic gabapentin on ethanol intake

An animal model of self-administration in dependent rats has been established and validated (Roberts et al., 1996; O'Dell et al., 2004). Figure $5 A$ illustrates operant responding for ethanol by dependent and nondependent rats $2 \mathrm{~h}$ after termination of ethanol vapor inhalation and $30 \mathrm{~min}$ after intraperitoneal injection of five doses of gabapentin. A two-way mixed-design ANOVA yielded a significant interaction effect of ethanol vapor history (betweensubjects factor) and gabapentin dose (within-subjects factor) on operant ethanol responding $\left(F_{(4,92)}=3.61 ; p<0.01\right)$ and ethanol intake (grams per kilogram; $\left.F_{(4,92)}=3.79, p<0.01\right)$. Chronic ethanol vapor exposure increased ethanol intake (grams per kilogram) in dependent rats relative to nondependent rats $(p<0.05)$, and that effect was attenuated by the three highest doses $(10,30$, and $120 \mathrm{mg} / \mathrm{kg}$ ) of gabapentin $(p>0.05 \mathrm{vs}$ nondependent controls). The two highest doses of gabapentin (30 and $120 \mathrm{mg} / \mathrm{kg}$ ) also significantly suppressed ethanol intake (grams per kilogram) by dependent animals relative to vehicle $(p<0.01$ in both cases). We obtained similar results with operant ethanol responses. No dose of gabapentin altered ethanol lever presses (grams per kilogram) by nondependent rats (Fig. $5 A$ ), nor did any dose of gabapentin alter water responding by any group of rats (Fig. $5 B)(p>0.05$ in all cases). Data for two dependent rats were excluded because those rats failed to exhibit reliable and elevated operant ethanol responding after chronic ethanol vapor exposure, and data for a third rat was excluded because the Geigy Extreme test revealed one of its datum to be an extreme outlier on a gabapentin test day.

We also investigated the effects of intra-CeA gabapentin on ethanol intake (grams per kilogram) by dependent and nondependent rats $6 \mathrm{~h}$ after removal of ethanol liquid diet and $30 \mathrm{~min}$ after intra-CeA infusion of two doses $(0,20 \mu \mathrm{g})$ of gabapentin. There was a significant interaction effect of ethanol vapor history and gabapentin versus vehicle on operant ethanol responding $\left(F_{(1,10)}=5.99 ; p=0.034\right)$ and ethanol intake (grams per kilogram; $F_{(1,10)}=6.32 ; p=0.031$, two-way mixed-design ANOVAs). Chronic exposure to ethanol liquid diet increased ethanol intake (grams per kilogram) in dependent rats relative to nondependent rats $(p<0.05)$, and this elevated ethanol intake by dependent animals was blocked by intra-CeA infusion of $20 \mu \mathrm{g}$ of gabapentin. We obtained similar results with operant ethanol responses. Operant water responding was not affected by liquid diet history or gabapentin infusion (data not shown) ( $p>0.05$ in all cases). Data for five rats (three dependent and two nondependent) were excluded because those rats were confirmed to have one or both cannulas placed inaccurately in the CeA. Gabapentin did not alter water responding by any group of rats $(p>0.05)$.

\section{Effects of gabapentin on anxiety-like behavior produced by an} acute bolus injection of ethanol

Acute bolus ethanol injection significantly decreased the percentage of time spent on open arms of the elevated plus maze $10 \mathrm{~h}$ after injection (after BALs returned to zero) relative to salineinjected controls (Fig. 6) $\left(t_{(14)}=2.25 ; p<0.05\right)$. Gabapentin dose-dependently increased the percentage of time spent in the open arms of the plus maze by ethanol-injected rats $\left(F_{(3,27)}=\right.$ $3.33 ; p<0.05)$. The highest dose of gabapentin $(120 \mathrm{mg} / \mathrm{kg})$ significantly attenuated the ethanol-induced decrease in the percentage of time spent on the open arms of the elevated plus maze $(p<0.01)$. Gabapentin did not affect the percentage of time spent in open arms of the elevated plus maze by ethanol-naive animals. Table 1 displays time spent in the open and closed arms during the 5 min plus-maze test. A separate two-way ANOVA indicated that animals injected with ethanol exhibited fewer closed arm entries during the plus-maze test relative to salineinjected controls $\left(F_{(1,54)}=6.04 ; p=0.017\right)$ (data not shown). There was no effect of gabapentin nor was there an interaction effect on closed arm entries.

\section{Discussion}

Our previous in vitro and in vivo findings showed that ethanol dependence is associated with increased GABAergic transmission in the CeA (Roberto et al., 2003, 2004a). Gabapentin is an analog of GABA with anticonvulsant properties, and it has been used to treat ethanol withdrawal in humans (Book and Myrick, 2005; Mariani et al., 2006; Bonnet et al., 2007; Myrick et al., 2007). However, little is known of its mechanism of action. The observation that gabapentin increases GABA release in brain slices led us to evaluate the effects of gabapentin on GABAergic transmission in rat CeA slices, and to explore the behavioral effects of gabapentin on anxiety and drinking in nondependent and dependent rats. Our electrophysiological findings show that gabapentin has strikingly different effects in nondependent and ethanoldependent rats, both cellularly and pharmacologically. In nondependent rats, gabapentin facilitated GABAergic transmission in 

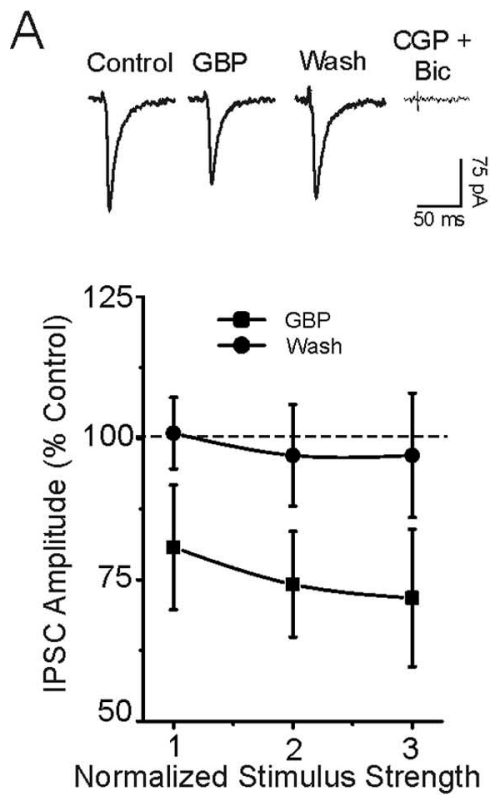
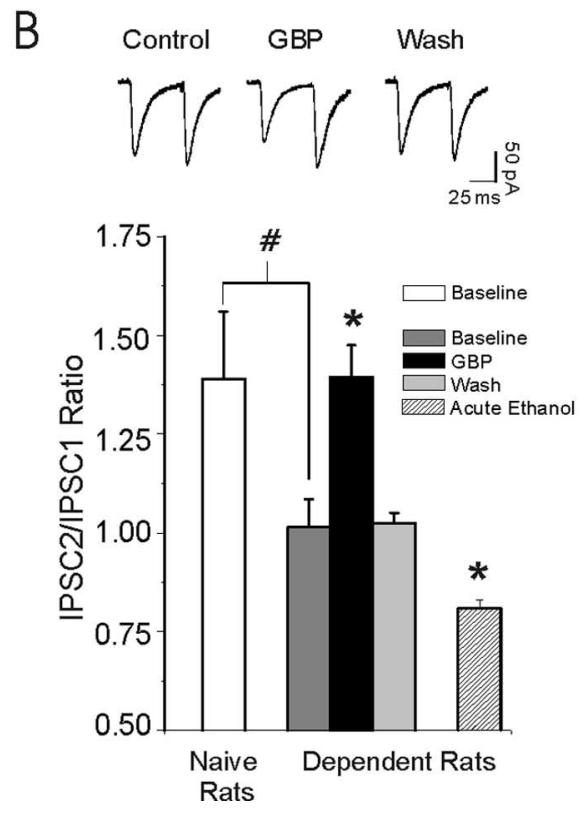
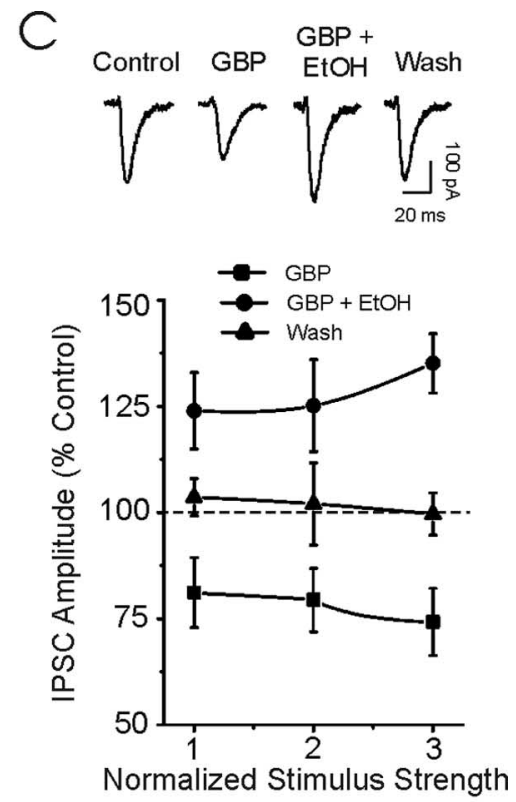

Figure 3. Gabapentin $(50 \mu \mathrm{M})$ reduces IPSC amplitudes in CeA neurons from ethanol-dependent rats. $\boldsymbol{A}$, Top, Representative evoked IPSCs from a CeA neuron of ethanol-dependent rat recorded under various treatment conditions. Superfusion of CGP 55845A and bicuculline completely blocked these IPSCs. Bottom, In contrast to slices from naive controls (see Fig. 1A), application of gabapentin for 10 min to slices from ethanol-dependent rats decreased IPSC amplitudes with recovery on washout. CGP 55845 A was not present in the bathing solution. $\boldsymbol{B}$, Top, Representative traces of PPF of IPSCs recorded under various treatment conditions from a dependent rat. Gabapentin increased PPF. Bottom, Pooled data showing that gabapentin (50 $\mu \mathrm{m})$ significantly $\left({ }^{*} p<0.05\right.$ ) increased PPF of GABA-IPSCs $(n=6)$, with recovery on washout. In dependent rats, ethanol alone significantly $\left({ }^{*} p<0.05\right)$ decreased PPF of GABA-IPSCs ( $\left.n=8\right)$ (Roberto et al., 2004a). As reported previously (Roberto et al., 2004a), in dependent rats, baseline PPF of IPSC s is significantly ( ${ }^{\#} p<0.05$ ) lower compared with that in nondependent rats. $C$, Top, Evoked IPSCs in CeA neurons from an ethanol-dependent rat recorded under various treatment conditions. Bottom, Pooled data of ethanol-gabapentin interactions. Acute ethanol overcame the depressive effect of gabapentin and significantly $(p<0.05 ; n=7)$ increased the mean amplitude of GABA-IPSPCs in CeA neurons, with recovery on washout. Error bars indicate SEM.

the CeA, but did not affect ethanol intake. However, in dependent rats, gabapentin decreased GABAergic transmission in the $\mathrm{CeA}$ and reduced excessive ethanol intake. Furthermore, gabapentin suppressed the anxiogenic-like effects of withdrawal from an acute alcohol injection.

It has been reported that gabapentin enhances GABA release from rat striatal brain slices (Gotz et al., 1993) and nonvesicular release of GABA in both rat optic nerves (Kocsis and Honmou, 1994) and rat hippocampal slices (Honmou et al., 1995). Here we find that gabapentin, like ethanol, increases GABAergic transmission in CeA slices from nondependent rats and decreases PPF of IPSCs, suggesting that its action is mediated, at least in part, by an increased release of GABA. However, in the CeA slices from nondependent rats, coapplication of ethanol and gabapentin additively increase GABA-IPSC amplitudes, suggesting that gabapentin and ethanol use different intracellular mechanisms to augment GABA-IPSCs in naive CeA. The gabapentin-induced augmentation of GABA-IPSCs was inhibited or occluded (at least in part) by a $\mathrm{GABA}_{\mathrm{B}}$ receptor antagonist, suggesting an important role for these receptors in the effects of gabapentin. Note, however, that $\mathrm{GABA}_{\mathrm{B}}$ receptors are not required for the enhancement of IPSCs by acute ethanol in the CeA, as we showed previously (Roberto et al., 2003).

A series of studies in other laboratories have shown that gabapentin effects involve $\mathrm{GABA}_{\mathrm{B}}$ receptors, at least in part (Xiong and Stringer, 1997; Stringer and Lorenzo, 1999; Parker et al., 2004). Gabapentin acts as an agonist at $\mathrm{GABA}_{\mathrm{B}}$ receptors coupled to VOCCs in mouse cultured neurons (Bertrand et al., 2001; van Hooft et al., 2002). Nevertheless, despite this compelling evidence, conventional binding studies failed to demonstrate a direct interaction between gabapentin and $\mathrm{GABA}_{\mathrm{B}}$ receptors (Lanneau et al., 2001; Jensen et al., 2002). Gabapentin also may bind the $\alpha-2-\delta$ type- 1 subunit of voltage-gated calcium channels, as has been reported in the spinal dorsal horn (Xiao et al., 2007). Further studies will be required to determine the exact molecular mechanisms underlying the effects of gabapentin and ethanol on GABA release at CeA synapses.

Another factor that may influence the wide range of gabapentin effects in different brain regions in slice preparations may be the wide range of gabapentin concentrations used between studies. The doses $(10-75 \mu \mathrm{M})$ of gabapentin used in the present study are similar to those tested in other cellular studies such as in rat entorhinal slices (10-100 $\mu \mathrm{M}$ ) (Cunningham et al., 2004; Brown and Randall, 2005) and rat trigeminal nucleus (30 $\mu \mathrm{M})$ (Maneuf et al., 2001). In contrast, low concentrations of gabapentin $(<5 \mu \mathrm{M})$ are effective in DRG (Yang et al., 2005) and high doses are required in cultured neurons $(1000 \mu \mathrm{M})$ (Cheng et al., 2006).

We previously found increased GABA "tone" in CeA after chronic ethanol exposure (Roberto et al., 2004a) and lack of tolerance for the acute ethanol effect (Roberto et al., 2004a). In the present study, gabapentin decreased GABA-IPSC amplitudes in CeA from ethanol-dependent rats by decreasing GABA release, "normalizing" the chronic ethanol-induced effect. However, ethanol still augmented the GABA-IPSCs even in the presence of gabapentin, further suggesting that these drugs may produce their effects via different mechanisms. Nonetheless, the gabapentin-induced decrease in GABAergic transmission in dependent rats might account for the attenuation of excessive ethanol intake. We speculate that during the development of ethanol dependence, neuroadaptative changes occur in the GABAergic system, including presynaptic $\mathrm{GABA}_{\mathrm{B}} \mathrm{R}$ function (e.g., a reduced sensitivity and/or downregulation of $\mathrm{GABA}_{\mathrm{B}}$ receptors). Our findings with CGP 55845A and baclofen support this hypothesis 
and suggest that alteration in $\mathrm{GABA}_{\mathrm{B}}$ receptor function could be responsible for the differential effects of gabapentin in naive versus ethanol dependent rats. Although $\mathrm{GABA}_{\mathrm{B}}$ receptors may not be involved in the acute ethanol effect in CeA neurons, they could be involved in the increased GABAergic tone and the gabapentin-induced depression of GABAIPSC amplitudes in CeA after chronic ethanol. Because there is evidence that $\mathrm{GABA}_{\mathrm{B}}$ receptors modulate ethanol action at both electrophysiological (Wan et al., 1996; Peris et al., 1997; Siggins et al., 2005; Weiner and Valenzuela, 2006) and behavioral levels (Castelli et al., 2005; Czachowski et al., 2006; Maccioni et al., 2007), future studies will assess possible changes in the expression of $\mathrm{GABA}_{\mathrm{B}}$ receptor subunit proteins and/or mRNA in CeA.

In the present study, systemic gabapentin injection dose-dependently blocked the anxiogenic-like effects associated with "hangover" after acute administration of a high ethanol dose, but did not affect anxiety-like behavior in ethanol-naive animals. Acute exposure to a high dose of alcohol reliably produces increases in anxiety-like behavior (Zhang et al., 2007) and a negative emotional state as measured by brain stimulation reward thresholds (Schulteis and Liu, 2006). These effects are amplified after multiple ethanol exposures (Schulteis and Liu, 2006; Zhang et al., 2007), suggesting a role for negative emotional states during early-stage alcohol use and in the subsequent transition to addiction. A similar correspondence has been observed in studies of opioid withdrawal where both rat and human studies have validated that acute withdrawal after single doses of drug mimics much of the pharmacology of acute withdrawal after chronic drugs (Stitzer et al., 1991; Schulteis et al., 2003).

Systemic gabapentin injection also dose-dependently suppressed increases in operant ethanol responding produced by withdrawal from chronic ethanol vapor in dependent rats, but did not alter ethanol self-administration in nondependent animals. This lack of gabapentin effect in nondependent rats is not likely attributable to a floor effect on operant responding for ethanol, because baseline responding of those animals for water was far lower than baseline responding for ethanol, and also because past findings from our group have presented substantially lower baseline operant ethanol responding in nondependent animals than those seen here (Valdez et al., 2002; Funk et al., 2006, 2007). The doses of systemically administered gabap-
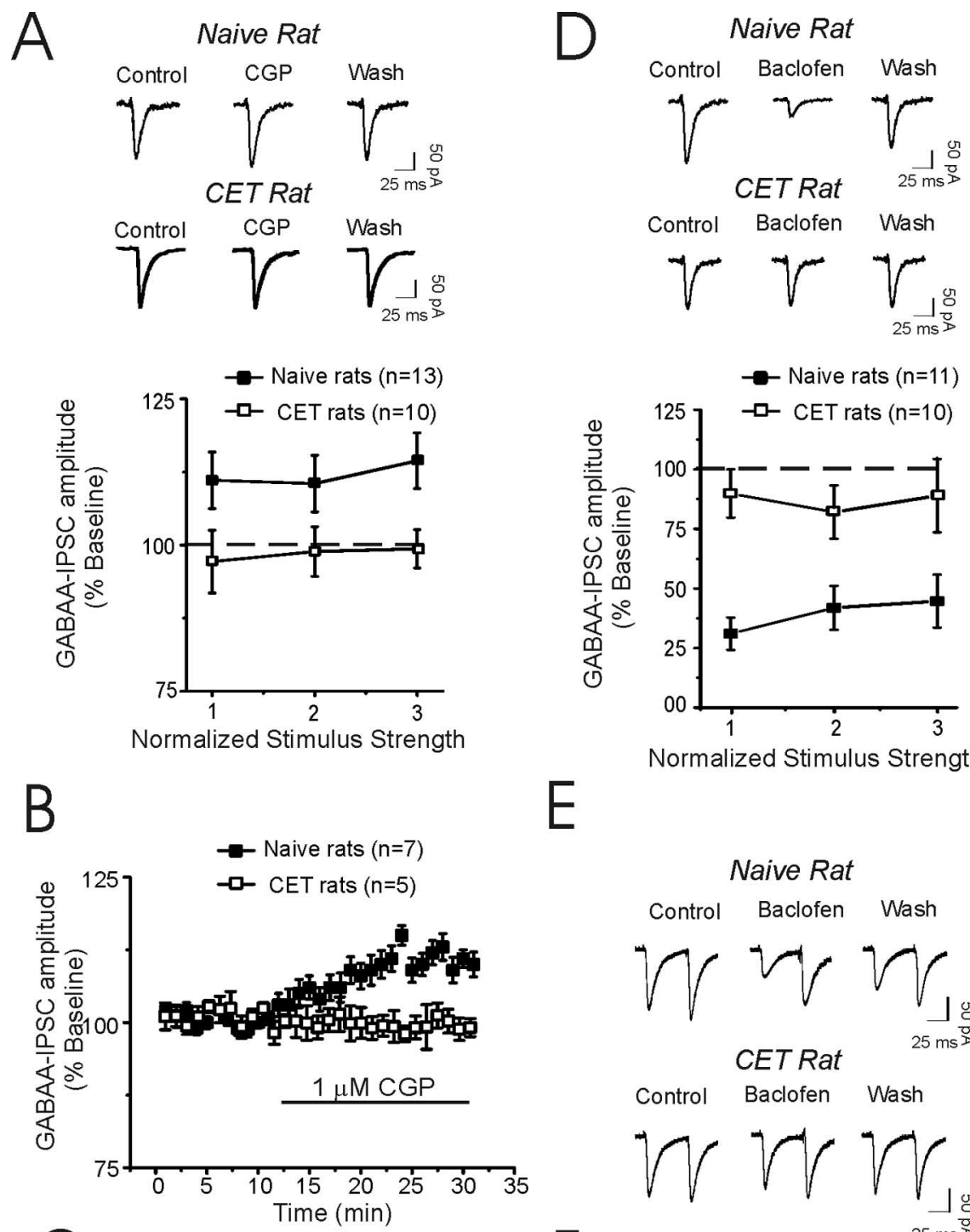

$\mathrm{E}$

Normalized Stimulus Strength
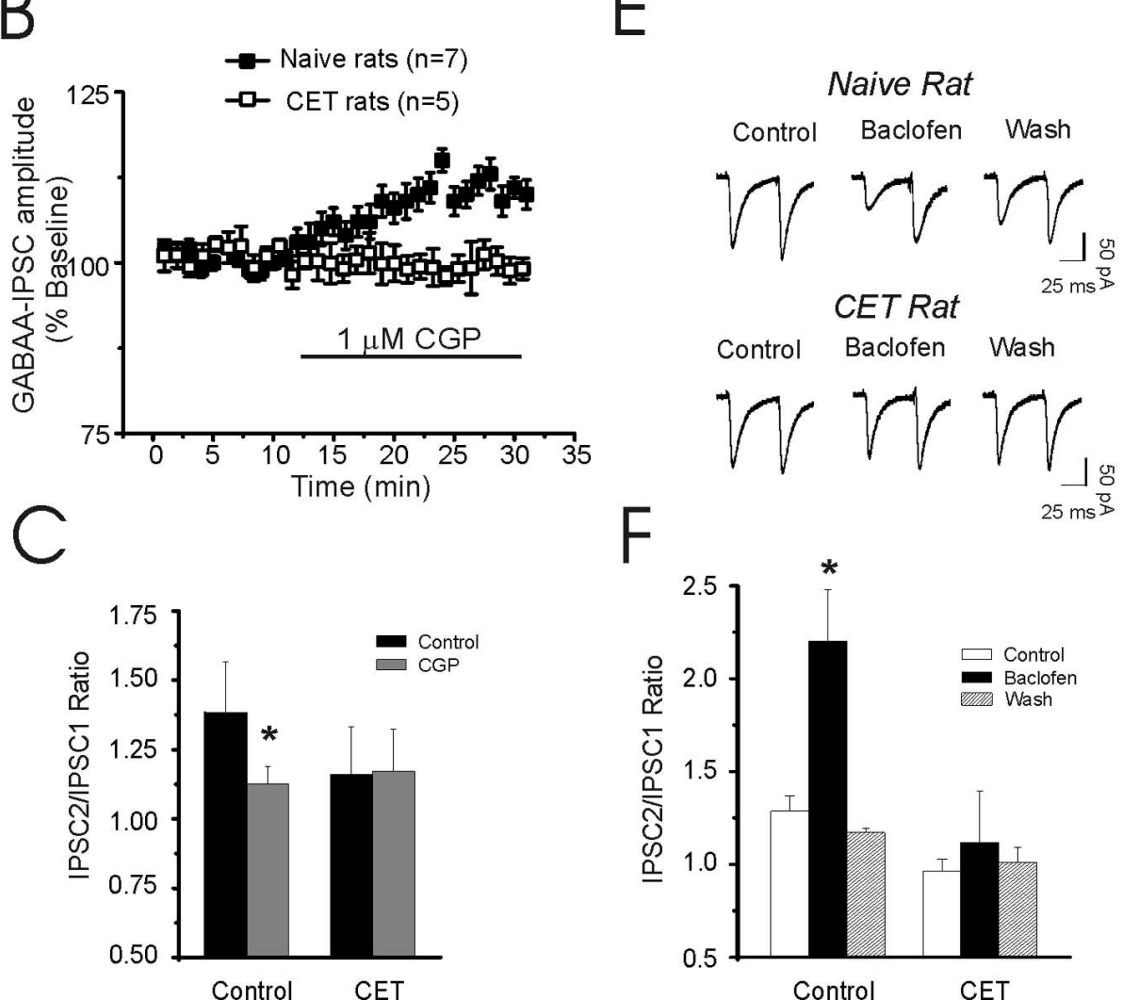

Figure 4. Effects of CGP and baclofen on IPSC amplitude in CeA. $A, I-0$ curve from CeA neurons of naive and ethanol-dependent rats. CGP 55845A (1 $\mu \mathrm{M})$ in the presence of APV and CNQX significantly $(p<0.05 ; n=13)$ increased mean IPSC sizes (averaged over all stimulus intensities) in naive animals. $\boldsymbol{B}$, Time course of mean IPSCs evoked by half maximal stimulus intensity recorded from CeA neurons from naive $(n=7)$ and ethanol-dependent $(n=5)$ rats. C, CGP 55845A also significantly $\left({ }^{*} p<0.05\right)$ decreased the mean PPF of IPSCS, but only in CeA from naive rats. $\boldsymbol{D}$, The $\mathrm{GABA}_{\mathrm{B}}$ receptor agonist baclofen $(10 \mu \mathrm{m})$ is less effective in CeA neurons taken from CET rats compared with naive rats. Superfusion of baclofen for 10 min markedly $(p<0.001)$ decreased the GABA-IPSC amplitudes in neurons from naive rats. In neurons from CET rats, the effects of baclofen were significantly $(p<$ 0.05 ) reduced, suggesting a decrease in $G_{B B A}$ receptor sensitivity after CET. $E$, Representative traces of a paired-pulse study (at 50 ms interstimulus intervals) of IPSCs in CeA neuron from naive (top) and CET (right) rats (bottom). $\boldsymbol{F}$, Pooled data of mean PPF ratios in neurons of naive and CET rats. Baclofen significantly $\left({ }^{*} p<0.05\right)$ increased PPF ratio of IPSC s in naive $(n=7)$ rats, but not in CET $(n=6)$ rats. Error bars indicate SEM. 


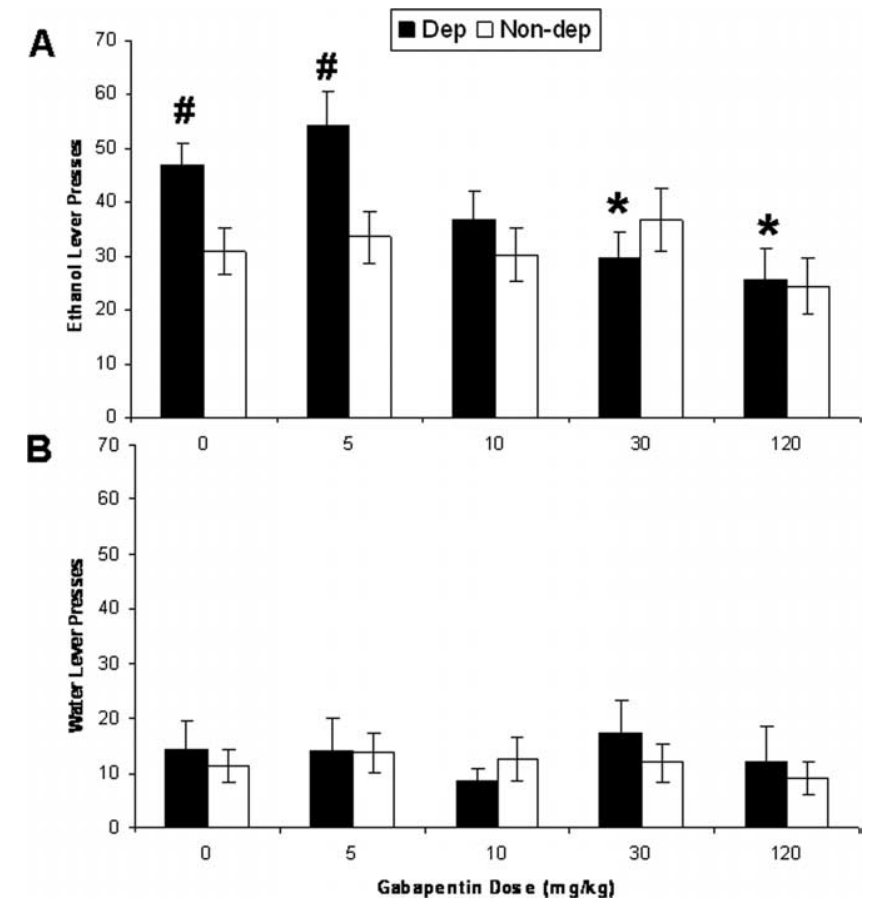

Figure 5. Gabapentin decreases ethanol intake. $\boldsymbol{A}$, The data reflect mean ( \pm SEM) "ethanol lever presses" or "operant ethanol responses" (grams per kilogram) by rats either exposed to chronic ethanol vapor (dependent rats; black bars; $n=11$ ) or not exposed to ethanol vapor (nondependent rats; white bars; $n=14$ ) after pretreatment with gabapentin. Rats were tested for 30 min operant ethanol self-administration $2 \mathrm{~h}$ after removal from vapor chambers and 30 min after injection of various doses $(0,5,10,30$, or $120 \mathrm{mg} / \mathrm{kg}$, i.p.; all rats injected with all doses of gabapentin in a Latin-square design) of gabapentin. Dependent rats consumed significantly more ethanol than nondependent rats, an effect that was blocked by the three highest doses $(10,30$, and $120 \mathrm{mg} / \mathrm{kg}$ ) of gabapentin. The two highest doses ( 30 and $120 \mathrm{mg} / \mathrm{kg}$ ) of gabapentin suppressed ethanol intake in dependent rats relative to saline injection. No dose of gabapentin affected ethanol intake by nondependent rats. ${ }^{*} p<0.05$, significant difference from vehicle ( $0 \mathrm{mg} / \mathrm{kg}$ gabapentin) in the same group of rats; ${ }^{\#} p<0.05$, significant difference from nondependent rats injected with the same gabapentin dose. $\boldsymbol{B}$, Gabapentin did not alter water responding by any group of rats (Fig. $6 B)(p>0.05$ in all cases).

entin that effectively reversed dependence-induced increases in anxiety-like behavior and ethanol self-administration in the present investigation are comparable with the range of gabapentin doses effective in treating other behavioral sequelae in rats, such as convulsive (Freitas et al., 2006) and nonconvulsive (Williams et al., 2006) seizures.

The role of the CeA in the systemic effects of gabapentin is strengthened by our findings that gabapentin infused directly into the CeA blocked dependence-induced increases in ethanol intake during withdrawal from an ethanol liquid diet. There was also a nonsignificant tendency for intra-CeA gabapentin to increase ethanol intake by nondependent rats, consistent with the opposite electrophysiological profiles of gabapentin in ethanoldependent versus ethanol-naive rats. It is worth reiterating that rats in the CeA local injection study were exposed to chronic ethanol liquid diet, whereas rats in the systemic study were exposed to chronic intermittent ethanol vapor. However, past findings from our lab indicate that these two procedures produce similar BALs in rats, and that exposed rats reliably exhibit somatic and motivational symptoms associated with alcohol dependence during withdrawal (Gilpin et al., unpublished findings).

Together, these results suggest that activation of GABA systems in the CeA may selectively suppress ethanol selfadministration by reversing a high-anxiety state that drives exces-

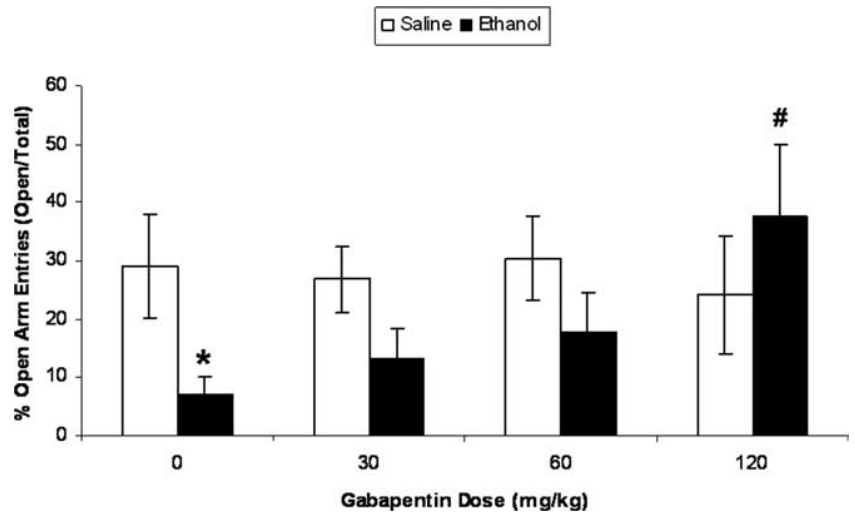

Figure 6. Gabapentin reverses ethanol-induced increases in anxiety-like behavior produced by acute bolus injection of ethanol. The data reflect the mean ( \pm SEM) percentage time spent in the open arms of an elevated plus maze during a 5 min test. Control rats spent $\sim 30 \%$ of the time in the open arms, and values that fall below controls reflect an increase in anxiety-like behavior because those animals spent less time in the open arms. We injected rats with either $10 \% \mathrm{w} / \mathrm{v}$ ethanol $(3 \mathrm{~g} / \mathrm{kg}$, i.p.) or an equivalent volume of saline. Ten hours later, we placed rats in the center of the plus maze and recorded the time spent in the open and closed arms. Thirty minutes before plus-maze testing, separate groups of rats were injected with various doses of gabapentin (0,30,60, or $120 \mathrm{mg} / \mathrm{kg}$, i.p.; $n=8-10$ per dose). Ethanol produced an increase in anxiety-like behavior that was dose-dependently reversed by pretreatment with gabapentin, whereas gabapentin did not affect anxiety-like behavior in saline-injected controls. ${ }^{*} p<0.05$ relative to saline control at same gabapentin dose; ${ }^{\#} p<0.01$ relative to ethanol-treated animals injected with vehicle.

sive drinking in dependent animals. These findings also suggest an important gabapentin-ethanol interaction on GABAergic transmission in CeA that markedly adapts during development of ethanol dependence. The mechanism of gabapentin influence on naive $\mathrm{CeA}$ may be associated with its action on $\mathrm{GABA}_{\mathrm{B}}$ receptors, although other mechanisms may be involved. CeA neurons are predominantly GABAergic (Sun and Cassell, 1993; Cassell et al., 1999), either local inhibitory interneurons or inhibitory projection neurons that target brain-stem or other nuclei, such as bed nucleus of the stria terminalis. The fine-tuning of the GABAergic inhibitory system in the $\mathrm{CeA}$ is thus a prerequisite for controlling both local and output neurons projecting to these downstream nuclei. Because GABAergic drugs are typically robust anxiolytics (Kalueff and Nutt, 2006), it may seem paradoxical that gabapentin [and other anxiolytics such as nociceptin (Roberto and Siggins, 2006) and cannabinoids (unpublished data)] would depress GABAergic transmission in a brain region known to be involved in stress-related behavior. However, because gabapentin selectively suppresses dependence-induced increases in ethanol intake and also opposes ethanol actions in CeA neurons from ethanoldependent rats, it may functionally influence neuronal responsivity of the inhibitory CeA gating that regulates information flow through the local intra-amygdaloidal circuits (e.g., by disinhibition of CeA), leading to an increased inhibition of the downstream regions.

The elimination of alcohol from blood after high-dose exposure (acute or chronic) produces increases in anxiety-like behavior in rodents, and that state is likely an important motivational factor in the compulsive ethanol-seeking behavior associated with ethanol dependence (Koob, 2006). Gabapentin, via modulation of GABAergic neurotransmission, may abolish this highanxiety state and thus normalize ethanol intake. Although the acute withdrawal time point used to explore the behavioral effects of gabapentin may not have direct relevance to the human clinical situation (humans do not tend to relapse during acute with- 
drawal), the withdrawal model effectively predicted the clinical efficacy of acamprosate (De Witte et al., 2005). Thus, our data may provide a similar rationale for the use of gabapentin as a potential treatment for certain components of the alcohol addiction cycle (Lee and Rodgers, 1990; Le et al., 1999; Anton et al., 2006; Heilig and Egli, 2006).

\section{References}

Andreasen M, Hablitz JJ (1994) Paired-pulse facilitation in the dentate gyrus: a patch-clamp study in rat hippocampus in vitro. J Neurophysiol 72:326-336.

Anton RF, O'Malley SS, Ciraulo DA, Cisler RA, Couper D, Donovan DM, Gastfriend DR, Hosking JD, Johnson BA, LoCastro JS, Longabaugh R, Mason BJ, Mattson ME, Miller WR, Pettinati HM, Randall CL, Swift R, Weiss RD, Williams LD, Zweben A (2006) Combined pharmacotherapies and behavioral interventions for alcohol dependence: the COMBINE study: a randomized controlled trial. JAMA 295:2003-2017.

Bertrand S, Ng GY, Purisai MG, Wolfe SE, Severidt MW, Nouel D, Robitaille R, Low MJ, O’Neill GP, Metters K, Lacaille JC, Chronwall BM, Morris SJ (2001) The anticonvulsant, antihyperalgesic agent gabapentin is an agonist at brain $\gamma$-aminobutyric acid type B receptors negatively coupled to voltage-dependent calcium channels. J Pharmacol Exp Ther 298:15-24.

Bonnet U, Banger M, Leweke FM, Maschke M, Kowalski T, Gastpar M (1999) Treatment of alcohol withdrawal syndrome with gabapentin. Pharmacopsychiatry 32:107-109.

Bonnet U, Specka M, Leweke FM, Nyhuis P, Banger M (2007) Gabapentin's acute effect on mood profile- a controlled study on patients with alcohol withdrawal. Prog Neuropsychopharmacol Biol Psychiatry 31:434-438.

Book SW, Myrick H (2005) Novel anticonvulsants in the treatment of alcoholism. Expert Opin Investig Drugs 14:371-376.

Bozikas V, Petrikis P, Gamvrula K, Savvidou I, Karavatos A (2002) Treatment of alcohol withdrawal with gabapentin. Prog Neuropsychopharmacol Biol Psychiatry 26:197-199.

Brown JT, Randall A (2005) Gabapentin fails to alter P/Q-type $\mathrm{Ca}^{2+}$ channel-mediated synaptic transmission in the hippocampus in vitro. Synapse 55:262-269.

Cassell MD, Freedman LJ, Shi C (1999) The intrinsic organization of the central extended amygdala. Ann NY Acad Sci 877:217-241.

Castelli MP, Pibiri F, Piras AP, Carboni G, Orru A, Gessa GL, Carai MA, Colombo G (2005) Differential G-protein coupling to GABAB receptor in limbic areas of alcohol-preferring and -nonpreferring rats. Eur J Pharmacol 523:67-70.

Cheng VY, Bonin RP, Chiu MW, Newell JG, MacDonald JF, Orser BA (2006) Gabapentin increases a tonic inhibitory conductance in hippocampal pyramidal neurons. Anesthesiology 105:325-333.

Cunningham MO, Woodhall GL, Thompson SE, Dooley DJ, Jones RS (2004) Dual effects of gabapentin and pregabalin on glutamate release at rat entorhinal synapses in vitro. Eur J Neurosci 20:1566-1576.

Czachowski CL, Legg BH, Stansfield KH (2006) Ethanol and sucrose seeking and consumption following repeated administration of the GABA(B) agonist baclofen in rats. Alcohol Clin Exp Res 30:812-818.

De Witte P, Littleton J, Parot P, Koob G (2005) Neuroprotective and abstinence-promoting effects of acamprosate: elucidating the mechanism of action. CNS Drugs 19:517-537.

Dierking G, Duedahl TH, Rasmussen ML, Fomsgaard JS, Moiniche S, Romsing J, Dahl JB (2004) Effects of gabapentin on postoperative morphine consumption and pain after abdominal hysterectomy: a randomized, double-blind trial. Acta Anaesthesiol Scand 48:322-327.

Dooley DJ, Donovan CM, Meder WP, Whetzel SZ (2002) Preferential action of gabapentin and pregabalin at $\mathrm{P} / \mathrm{Q}$-type voltage-sensitive calcium channels: inhibition of $\mathrm{K}^{+}$-evoked [3H]-norepinephrine release from rat neocortical slices. Synapse 45:171-190.

Fink K, Meder W, Dooley DJ, Gothert M (2000) Inhibition of neuronal $\mathrm{Ca}^{2+}$ influx by gabapentin and subsequent reduction of neurotransmitter release from rat neocortical slices. Br J Pharmacol 130:900-906.

Freitas RM, Sousa FC, Viana GS, Fonteles MM (2006) Effect of gabaergic, glutamatergic, antipsychotic and antidepressant drugs on pilocarpineinduced seizures and status epilepticus. Neurosci Lett 408:79-83.

Funk CK, O’Dell LE, Crawford EF, Koob GF (2006) Corticotropin-releasing factor within the central nucleus of the amygdala mediates enhanced ethanol self-administration in withdrawn, ethanol-dependent rats. J Neurosci 26:11324-11332.

Funk CK, Zorrilla EP, Lee MJ, Rice KC, Koob GF (2007) Corticotropinreleasing factor 1 antagonists selectively reduce ethanol selfadministration in ethanol-dependent rats. Biol Psychiatry 61:78-86.

Gentry JR, Hill C, Malcolm R (2002) New anticonvulsants: a review of applications for the management of substance abuse disorders. Ann Clin Psychiatry 14:233-245.

Gotz E, Feuerstein TJ, Lais A, Meyer DK (1993) Effects of gabapentin on release of gamma-aminobutyric acid from slices of rat neostriatum. Arzneimittelforschung 43:636-638.

Heilig M, Egli M (2006) Pharmacological treatment of alcohol dependence: target symptoms and target mechanisms. Pharmacol Ther 111:855-876.

Honmou O, Oyelese AA, Kocsis JD (1995) The anticonvulsant gabapentin enhances promoted release of GABA in hippocampus: a field potential analysis. Brain Res 692:273-277.

Jensen AA, Mosbacher J, Elg S, Lingenhoehl K, Lohmann T, Johansen TN, Abrahamsen B, Mattsson JP, Lehmann A, Bettler B, Brauner-Osborne H (2002) The anticonvulsant gabapentin (neurontin) does not act through gamma-aminobutyric acid-B receptors. Mol Pharmacol 61:1377-1384.

Jung ME, Wallis CJ, Gatch MB, Lal H (2000) Abecarnil and alprazolam reverse anxiety-like behaviors induced by ethanol withdrawal. Alcohol 21:161-168.

Kalueff AV, Nutt DJ (2006) Role of GABA in anxiety and depression. Depress Anxiety 24:495-517.

Kocsis JD, Honmou O (1994) Gabapentin increases GABA-induced depolarization in rat neonatal optic nerve. Neurosci Lett 169:181-184.

Koob GF (2006) The neurobiology of addiction: a hedonic Calvinist view. New York: Guilford.

Lal H, Prather PL, Rezazadeh SM (1991) Anxiogenic behavior in rats during acute and protracted ethanol withdrawal: reversal by buspirone. Alcohol 8:467-471.

Lanneau C, Green A, Hirst WD, Wise A, Brown JT, Donnier E, Charles KJ, Wood M, Davies CH, Pangalos MN (2001) Gabapentin is not a GABA receptor agonist. Neuropharmacology 41:965-975.

Le AD, Poulos CX, Harding S, Watchus J, Juzytsch W, Shaham Y (1999) Effects of naltrexone and fluoxetine on alcohol self-administration and reinstatement of alcohol seeking induced by priming injections of alcohol and exposure to stress. Neuropsychopharmacology 21:435-444.

Lee C, Rodgers RJ (1990) Antinociceptive effects of elevated plus-maze exposure: influence of opiate receptor manipulations. Psychopharmacology (Berl) 102:507-513.

Maccioni P, Pes D, Orru A, Froestl W, Gessa GL, Carai MA, Colombo G (2007) Reducing effect of the positive allosteric modulator of the GABA(B) receptor, GS39,783, on alcohol self-administration in alcoholpreferring rats. Psychopharmacology (Berl) 193:171-178.

Maneuf YP, Hughes J, McKnight AT (2001) Gabapentin inhibits the substance P-facilitated $\mathrm{K}(+)$-evoked release of $[(3) \mathrm{H}]$ glutamate from rat caudial trigeminal nucleus slices. Pain 93:191-196.

Mariani JJ, Rosenthal RN, Tross S, Singh P, Anand OP (2006) A random- 
ized, open-label, controlled trial of gabapentin and phenobarbital in the treatment of alcohol withdrawal. Am J Addict 15:76-84.

Morse AC, Schulteis G, Holloway FA, Koob GF (2000) Conditioned place aversion to the "hangover" phase of acute ethanol administration in the rat. Alcohol 22:19-24.

Myrick H, Anton R, Voronin K, Wang W, Henderson S (2007) A doubleblind evaluation of gabapentin on alcohol effects and drinking in a clinical laboratory paradigm. Alcohol Clin Exp Res 31:221-227.

Ng GY, Bertrand S, Sullivan R, Ethier N, Wang J, Yergey J, Belley M, Trimble L, Bateman K, Alder L, Smith A, McKernan R, Metters K, O'Neill GP, Lacaille JC, Hebert TE (2001) Gamma-aminobutyric acid type B receptors with specific heterodimer composition and postsynaptic actions in hippocampal neurons are targets of anticonvulsant gabapentin action. Mol Pharmacol 59:144-152.

Nie Z, Madamba SG, Siggins GR (2000) Ethanol enhances gammaaminobutyric acid responses in a subpopulation of nucleus accumbens neurons: role of metabotropic glutamate receptors. J Pharmacol Exp Ther 293:654-661.

O'Dell LE, Roberts AJ, Smith RT, Koob GF (2004) Enhanced alcohol selfadministration after intermittent versus continuous alcohol vapor exposure. Alcohol Clin Exp Res 28:1676-1682.

Pappagallo M (2003) Newer antiepileptic drugs: possible uses in the treatment of neuropathic pain and migraine. Clin Ther 25:2506-2538.

Parker DA, Ong J, Marino V, Kerr DI (2004) Gabapentin activates presynaptic $\mathrm{GABA}_{\mathrm{B}}$ heteroreceptors in rat cortical slices. Eur J Pharmacol 495:137-143.

Paxinos G, Watson C (1986) The rat brain in stereotaxic coordinates, Ed 2. San Diego: Academic

Peris J, Eppler B, Hu M, Walker DW, Hunter BE, Mason K, Anderson KJ (1997) Effects of chronic ethanol exposure on GABA receptors and GABAB receptor modulation of $3 \mathrm{H}-\mathrm{GABA}$ release in the hippocampus. Alcohol Clin Exp Res 21:1047-1052.

Roberto M, Siggins GR (2006) Nociceptin/orphanin FQ presynaptically decreases GABAergic transmission and blocks the ethanol-induced increase of GABA release in central amygdala. Proc Natl Acad Sci USA 103:9715-9720.

Roberto M, Madamba SG, Moore SD, Tallent MK, Siggins GR (2003) Ethanol increases GABAergic transmission at both pre- and postsynaptic sites in rat central amygdala neurons. Proc Natl Acad Sci USA 100:2053-2058.

Roberto M, Madamba SG, Stouffer DG, Parsons LH, Siggins GR (2004a) Increased GABA release in the central amygdala of ethanol-dependent rats. J Neurosci 24:10159-10166.

Roberto M, Schweitzer P, Madamba SG, Stouffer DG, Parsons LH, Siggins GR (2004b) Acute and chronic ethanol alter glutamatergic transmission in rat central amygdala: an in vitro and in vivo analysis. J Neurosci 24:1594-1603.

Roberts AJ, Cole M, Koob GF (1996) Intra-amygdala muscimol decreases operant ethanol self-administration in dependent rats. Alcohol Clin Exp Res 20:1289-1298.

Rogers J, Wiener SG, Bloom FE (1979) Long-term ethanol administration methods for rats: advantages of inhalation over intubation or liquid diets. Behav Neural Biol 27:466-486.

Schulteis G, Liu J (2006) Brain reward deficits accompany withdrawal (hangover) from acute ethanol in rats. Alcohol 39:21-28.

Schulteis G, Morse AC, Liu J (2003) Repeated experience with naloxone facilitates acute morphine withdrawal: potential role for conditioning processes in acute opioid dependence. Pharmacol Biochem Behav 76:493-503.

Siggins GR, Roberto M, Nie Z (2005) The tipsy terminal: presynaptic effects of ethanol. Pharmacol Ther 107:80-98.

Sills GJ (2006) The mechanisms of action of gabapentin and pregabalin. Curr Opin Pharmacol 6:108-113.

Stitzer ML, Wright C, Bigelow GE, June HL, Felch LJ (1991) Time course of naloxone-precipitated withdrawal after acute methadone exposure in humans. Drug Alcohol Depend 29:39-46.

Stringer JL, Lorenzo N (1999) The reduction in paired-pulse inhibition in the rat hippocampus by gabapentin is independent of $\mathrm{GABA}(\mathrm{B})$ receptor receptor activation. Epilepsy Res 33:169-176.

Sun N, Cassell MD (1993) Intrinsic GABAergic neurons in the rat central extended amygdala. J Comp Neurol 330:381-404.

Taylor CP, Gee NS, Su TZ, Kocsis JD, Welty DF, Brown JP, Dooley DJ, Boden P, Singh L (1998) A summary of mechanistic hypotheses of gabapentin pharmacology. Epilepsy Res 29:233-249.

Valdez GR, Roberts AJ, Chan K, Davis H, Brennan M, Zorrilla EP, Koob GF (2002) Increased ethanol self-administration and anxiety-like behavior during acute ethanol withdrawal and protracted abstinence: regulation by corticotropin-releasing factor. Alcohol Clin Exp Res 26:1494-1501.

van Hooft JA, Dougherty JJ, Endeman D, Nichols RA, Wadman WJ (2002) Gabapentin inhibits presynaptic $\mathrm{Ca}^{2+}$ influx and synaptic transmission in rat hippocampus and neocortex. Eur J Pharmacol 449:221-228.

Voris J, Smith NL, Rao SM, Thorne DL, Flowers QJ (2003) Gabapentin for the treatment of ethanol withdrawal. Subst Abus 24:129-132.

Wan FJ, Berton F, Madamba SG, Francesconi W, Siggins GR (1996) Low ethanol concentrations enhance GABAergic inhibitory postsynaptic potentials in hippocampal pyramidal neurons only after block of $\mathrm{GABA}_{\mathrm{B}}$ receptors. Proc Natl Acad Sci USA 93:5049-5054.

Watson WP, Robinson E, Little HJ (1997) The novel anticonvulsant, gabapentin, protects against both convulsant and anxiogenic aspects of the ethanol withdrawal syndrome. Neuropharmacology 36:1369-1375.

Weiner JL, Valenzuela CF (2006) Ethanol modulation of GABAergic transmission: the view from the slice. Pharmacol Ther 111:533-554.

Williams AJ, Bautista CC, Chen RW, Dave JR, Lu XC, Tortella FC, Hartings JA (2006) Evaluation of gabapentin and ethosuximide for treatment of acute nonconvulsive seizures following ischemic brain injury in rats. J Pharmacol Exp Ther 318:947-955.

Xiao W, Boroujerdi A, Bennett GJ, Luo ZD (2007) Chemotherapy-evoked painful peripheral neuropathy: analgesic effects of gabapentin and effects on expression of the alpha-2-delta type-1 calcium channel subunit. Neuroscience 144:714-720.

Xiong ZQ, Stringer JL (1997) Effects of felbamate, gabapentin and lamotrigine on seizure parameters and excitability in the rat hippocampus. Epilepsy Res 27:187-194.

Yang RH, Xing JL, Duan JH, Hu SJ (2005) Effects of gabapentin on spontaneous discharges and subthreshold membrane potential oscillation of type A neurons in injured DRG. Pain 116:187-193.

Zhang Z, Morse AC, Koob GF, Schulteis G (2007) Dose- and timedependent expression of anxiety-like behavior in the elevated plus maze during withdrawal from acute and repeated intermittent ethanol intoxication in rats. Alcohol Clin Exp Res 31:1811-1819. 